Does vitamin $\mathrm{C}$ enhance nitric oxide bioavailability in a tetrahydrobiopterin-dependent manner?

In vitro, in vivo and clinical studies

Mortensen, Alan; Lykkesfeldt, Jens

Published in:

Nitric Oxide: Biology and Chemistry

DOI:

10.1016/j.niox.2013.12.001

Publication date:

2014

Document version

Early version, also known as pre-print

Citation for published version (APA):

Mortensen, A., \& Lykkesfeldt, J. (2014). Does vitamin C enhance nitric oxide bioavailability in a

tetrahydrobiopterin-dependent manner? In vitro, in vivo and clinical studies. Nitric Oxide: Biology and Chemistry, 36, 51-57. https://doi.org/10.1016/j.niox.2013.12.001 
Provided for non-commercial research and education use. Not for reproduction, distribution or commercial use.

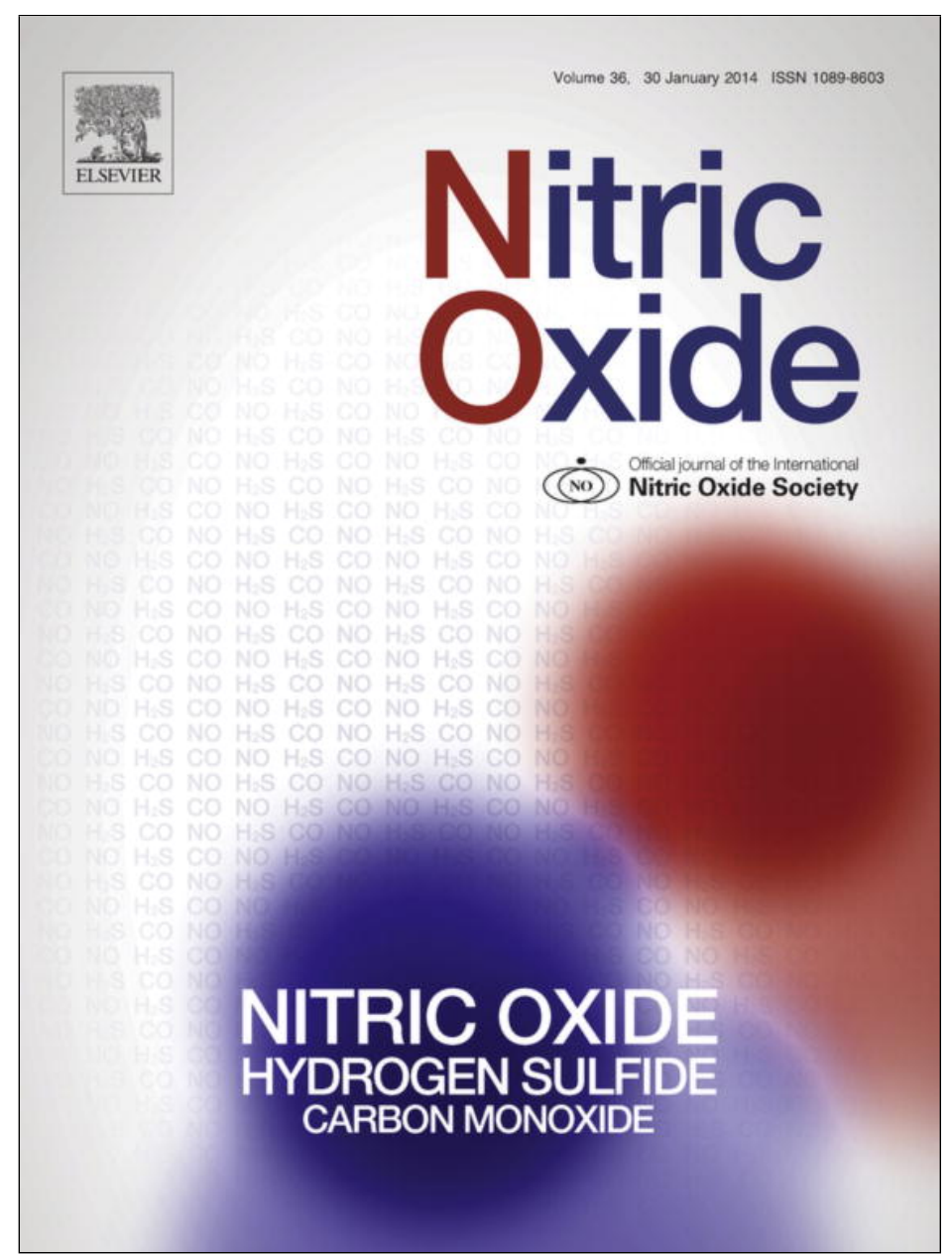

This article appeared in a journal published by Elsevier. The attached copy is furnished to the author for internal non-commercial research and education use, including for instruction at the authors institution and sharing with colleagues.

Other uses, including reproduction and distribution, or selling or licensing copies, or posting to personal, institutional or third party websites are prohibited.

In most cases authors are permitted to post their version of the article (e.g. in Word or Tex form) to their personal website or institutional repository. Authors requiring further information regarding Elsevier's archiving and manuscript policies are encouraged to visit:

http://www.elsevier.com/authorsrights 
Review

\title{
Does vitamin $C$ enhance nitric oxide bioavailability in a tetrahydrobiopterin-dependent manner? In vitro, in vivo and clinical studies
}

\author{
Alan Mortensen, Jens Lykkesfeldt* \\ Faculty of Health and Medical Sciences, University of Copenhagen, Denmark
}

\section{A R T I C L E I N F O}

\section{Article history:}

Received 19 July 2013

Revised 9 October 2013

Available online 9 December 2013

\section{Keywords:}

Tetrahydrobiopterin

Dihydrobiopterin

Ascorbate

Nitric oxide bioavailability

\begin{abstract}
A B S T R A C T
Ascorbate (Asc) has been shown to increase nitric oxide (NO) bioavailability and thereby improve endothelial function in patients showing signs of endothelial dysfunction. Tetrahydrobiopterin $\left(\mathrm{BH}_{4}\right)$ is a cofactor of endothelial nitric oxide synthase (eNOS) which may easily become oxidized to the inactive form dihydrobiopterin $\left(\mathrm{BH}_{2}\right)$. Asc may increase NO bioavailability by a number of mechanisms involving $\mathrm{BH}_{4}$ and eNOS. Asc increases $\mathrm{BH}_{4}$ bioavailability by either reducing oxidized $\mathrm{BH}_{4}$ or preventing $\mathrm{BH}_{4}$ from becoming oxidized in the first place. Asc could also increase $\mathrm{NO}$ bioavailability in a $\mathrm{BH}_{4}$-independent manner by increasing eNOS activity by changing its phosphorylation and S-nitrosylation status or by upregulating eNOS expression. In this review, we discuss the putative mechanisms by which Asc may increase NO bioavailability through its interactions with $\mathrm{BH}_{4}$ and eNOS.
\end{abstract}

(c) 2013 Elsevier Inc. All rights reserved.

\section{Contents}

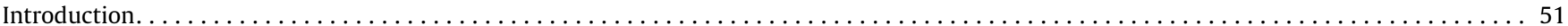

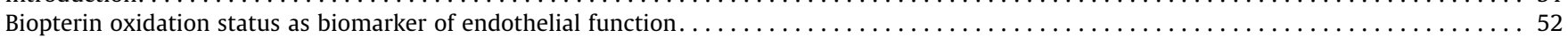

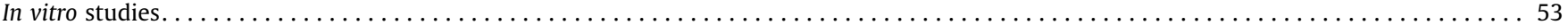

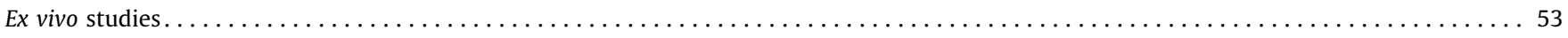

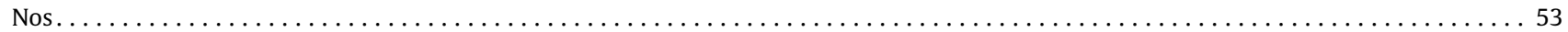

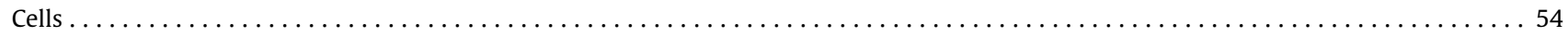

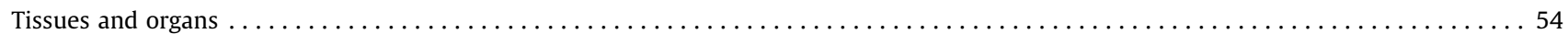

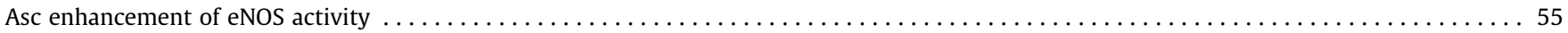

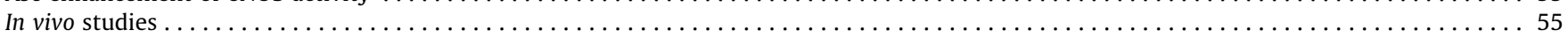

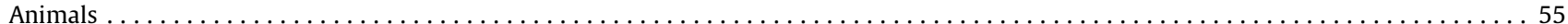

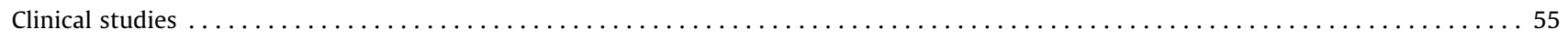

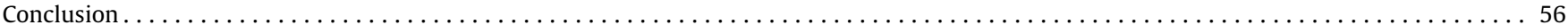

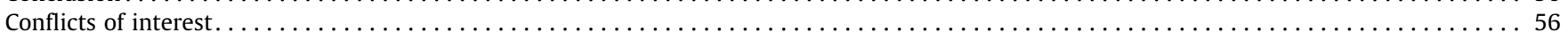

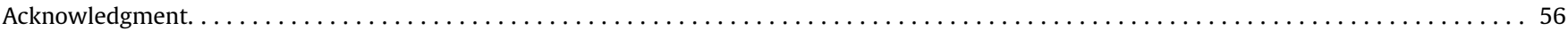

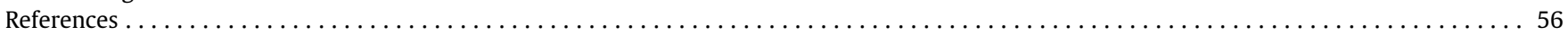

\section{Introduction}

Tetrahydrobiopterin (Fig. 1) is an endogenous co-factor of eight human enzymes: four aromatic amino acid hydroxylases, three nitric oxide synthases and alkylglycerol monooxygenase [1]. The

\footnotetext{
* Corresponding author. Address: Faculty of Health and Medical Sciences, University of Copenhagen, Ridebanevej 9, 1, DK-1870 Frederiksberg C, Denmark.

E-mail address: jopl@sund.ku.dk (J. Lykkesfeldt).
}

three nitric oxide synthases (NOS) are neuronal NOS (nNOS or NOS1), inducible NOS (iNOS or NOS2) and endothelial NOS (eNOS or NOS3). NOS produces the vaso-relaxing factor nitric oxide (NO) in a process involving conversion of L-arginine to L-citrulline, and tetrahydrobiopterin is thus important for regulating blood pressure. The active form of NOS producing NO is dimeric and one of the roles of tetrahydrobiopterin is to stabilize this dimer [2].

Biopterin exists in three stable oxidation states: tetrahydrobiopterin $\left(\mathrm{BH}_{4}\right)$, dihydrobiopterin $\left(\mathrm{BH}_{2}\right)$ and biopterin. Besides these, 
<smiles>CC(O)C(O)C1CNc2nc(N)[nH]c(=O)c2N1</smiles>

Tetrahydrobiopterin<smiles>O=C1OC(C(O)CO)C(O)=C1O</smiles>

Ascorbic acid<smiles>CC(O)C(O)C1=Nc2c(nc(N)[nH]c2=O)NC1</smiles>

Dihydrobiopterin<smiles>O=C1OC(C(O)CO)C(=O)C1=O</smiles>

Dehydroascorbic acid

Fig. 1. Structures of tetrahydrobiopterin, dihydrobiopterin, ascorbic acid and dehydroascorbic acid.

unstable short-lived intermediates such as the trihydrobiopterin radical and quinoid dihydrobiopterin exist. The most reduced form, $\mathrm{BH}_{4}$, is easily oxidized to a quinoid form of $\mathrm{BH}_{2}, \mathrm{qBH}_{2}$, which rapidly rearranges to $\mathrm{BH}_{2} ; \mathrm{BH}_{2}$ may then be further oxidized to biopterin. However, in contrast to $\mathrm{BH}_{4}, \mathrm{BH}_{2}$ is relatively stable and is only slowly oxidized [3].

$\mathrm{BH}_{4}$ and $\mathrm{BH}_{2}$ have been shown to bind to eNOS with similar affinity $\left(K_{\mathrm{d}} \approx 80 \mathrm{nM}\right)$ [4]. However, while binding of $\mathrm{BH}_{4}$ to NOS leads to formation of $\mathrm{NO}$, binding of $\mathrm{BH}_{2}$ completely inhibits the formation of $\mathrm{NO}$ [5] and instead leads to formation of superoxide [6]; a NOS state referred to as uncoupled. Because of this competition for binding to NOS, it could be expected that it is the ratio of $\mathrm{BH}_{4}$-to- $\mathrm{BH}_{2}$ that is important in determining superoxide and NO production, and hence endothelial dysfunction, rather than the absolute amount of $\mathrm{BH}_{4}$. Indeed, in a number of studies this association has been observed.

Ascorbate (Asc), the reduced form of vitamin C, is an important intracellular and circulatory antioxidant and has been suggested to play an important role in maintaining $\mathrm{BH}_{4}$ in its reduced state. Thus, in vitro studies have shown that ascorbate selectively reduces the $\mathrm{BH}_{3}$. radical to $\mathrm{BH}_{4}$, i.e., the one-electron oxidation product $[7,8]$. Also, Asc have been suggested to non-selectively spare $\mathrm{BH}_{4}$ from oxidation through its generic antioxidant function [8]. In this way, Asc may indirectly improve vascular function by increasing the bioavailability of NO in vivo. In these processes, Asc itself is oxidized to the ascorbyl free radical, two molecules of which dismutate into one molecule of Asc and one of dehydroascorbic acid
(DHA), the fully oxidized form of vitamin C (Fig. 2). In order to prevent loss of vitamin $C$ through oxidation, dehydroascorbic acid is rapidly reduced to Asc intracellularly by e.g., glutathione or thioredoxin reductase in a number of cell types - so called ascorbate recycling [9]. An intimate relationship between Asc, BH4 and NO production would provide a rationale partly explaining the significant relationship between poor vitamin C status and cardiovascular disease risk that has consistently been reported from large epidemiological studies [10]. However, until now in vivo and clinical studies investigating this role of Asc have been quite few.

This review discusses the available experimental literature on the putative role of Asc in NO bioavailability through interactions with $\mathrm{BH}_{4}$ and NOS.

\section{Biopterin oxidation status as biomarker of endothelial function}

A number of studies have pointed out that the ratio of $\mathrm{BH}_{4}$-to$\mathrm{BH}_{2}$ may be a better biomarker of superoxide and nitric oxide production, and hence endothelial function, than absolute levels of $\mathrm{BH}_{4}$. Crabtree and co-workers found that $\mathrm{NO}$ bioactivity correlated with intracellular $\mathrm{BH}_{4}$-to- $\mathrm{BH}_{2}$ ratio and not absolute levels of $\mathrm{BH}_{4}$, and that superoxide production was negatively correlated with $\mathrm{BH}_{4}$-to- $\mathrm{BH}_{2}$ ratio [4]. Flow-mediated vasodilation was found to be positively correlated with $\mathrm{BH}_{4}$ plasma levels and negatively correlated with $\mathrm{BH}_{2}$ plasma levels in patients with cardiovascular disorders; hence, a very strong positive correlation between flow-

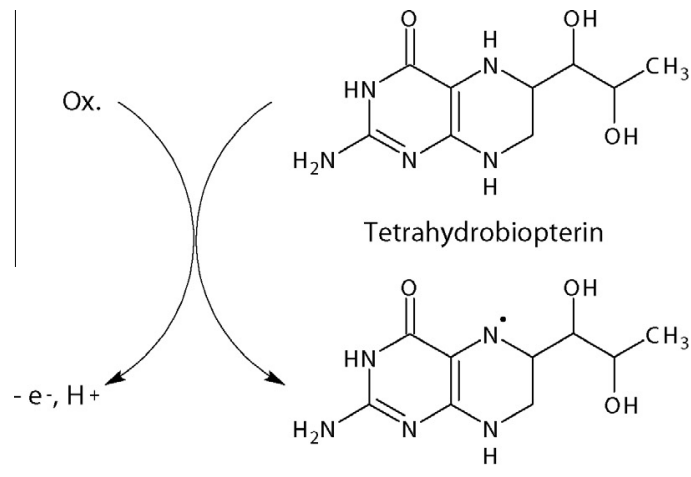

Trihydrobiopterin radical

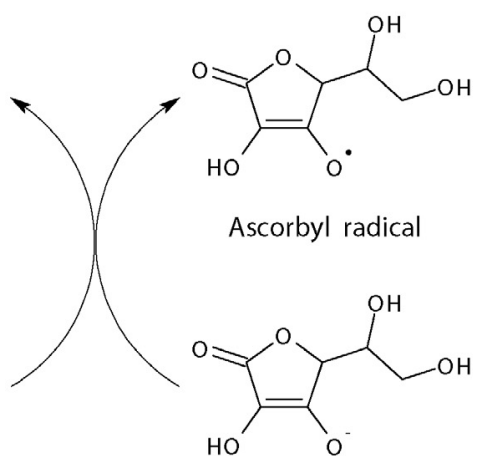

Ascorbate

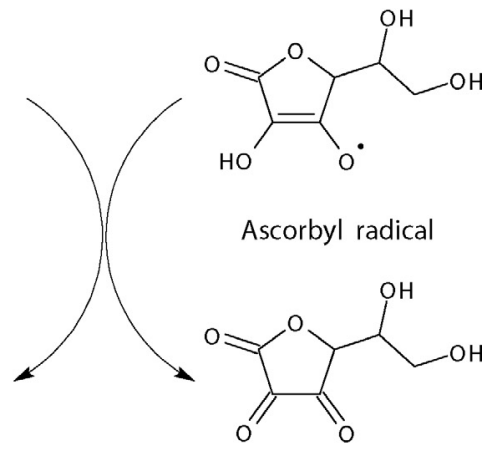

Dehydroascorbic acid

Fig. 2. Oxidation of tetrahydrobiopterin to the trihydrobiopterin radical followed by reduction by ascorbate with concomitant formation of the ascorbyl radical, two of which can dismutate yielding ascorbate and dihydroascorbic acid. 
mediated vasodilation and $\mathrm{BH}_{4}$-to- $\mathrm{BH}_{2}$ ratio was observed [11]. Likewise, in rats treated to increase the amount of $\mathrm{BH}_{2}$ and hence lower the $\mathrm{BH}_{4}$-to- $\mathrm{BH}_{2}$ ratio, evidence of uncoupling of NOS leading to increased superoxide production was found [12]. Also, acetylcholine-induced vasorelaxation was reduced in the aorta of rats with lower $\mathrm{BH}_{4}$-to- $\mathrm{BH}_{2}$ ratio and mean blood pressure was found to be negatively correlated with aortic $\mathrm{BH}_{4}$-to- $\mathrm{BH}_{2}$ ratio [12]. In another study, it was found that both $\mathrm{BH}_{4}$ and $\mathrm{BH}_{2}$ increased in rats that had undergone arteriovenous fistula (AVF) surgery compared to sham operated rats [13]. Despite the higher $\mathrm{BH}_{4}$ levels in AVF rats, superoxide production was increased in AVF rats and this was attributed to a lower $\mathrm{BH}_{4}$-to- $\mathrm{BH}_{2}$ ratio in these rats [13]. In ApoE-deficient mice, Asc in the feed decreased the aortic level of $\mathrm{BH}_{2}$ without influencing the level of $\mathrm{BH}_{4}$ resulting in an increased $\mathrm{BH}_{4}$-to- $\mathrm{BH}_{2}$ level which correlated with an increase in NOS activity [14]. Finally, computational studies confirmed that the ratio of $\mathrm{BH}_{4}$-to- $\mathrm{BH}_{2}$ is important for the formation of $\mathrm{NO}$ and superoxide from NOS [15].

\section{In vitro studies}

As $\mathrm{BH}_{4}$ is easily oxidized, it may easily be envisaged that an antioxidant-such as vitamin $\mathrm{C}$-may enhance the stability of $\mathrm{BH}_{4}$ and maintain a high ratio of $\mathrm{BH}_{4}$-to- $\mathrm{BH}_{2}$. As expected, Asc has been shown in several in vitro studies to be able to stabilize $\mathrm{BH}_{4}$. First of all, the rate of autoxidation of $\mathrm{BH}_{4}$ is dependent on the concentration of $\mathrm{BH}_{4}$, at least at low $\mathrm{pH}$, which is important to bear in mind when comparing stability studies performed at different concentrations. Thus, $41 \mathrm{nM} \mathrm{BH}_{4}$ was completely converted to $\mathrm{BH}_{2}$ in 15 min at $4{ }^{\circ} \mathrm{C}$ in $0.1 \mathrm{M} \mathrm{HCl}$, whereas $\mathrm{BH}_{4}$ in a $415 \mathrm{nM}$ solution under the same conditions was only $1 \%$ degraded and at higher concentrations of $\mathrm{BH}_{4}$ an even smaller percentage was oxidized [16]. Secondly, the stability of $\mathrm{BH}_{4}$ in aqueous solution is dependent on $\mathrm{pH}$ showing increased stability at low $\mathrm{pH}$ [3]. In Table 1 is summarized the observed effects of Asc on the stability of $\mathrm{BH}_{4}$ in vitro. From these studies it seems that the protective effect of Asc is modest at $\mathrm{pH} 7.4$.

The question is whether the protective effect of Asc is due to Asc being able to reduce oxidized $\mathrm{BH}_{4}$ or because Asc scavenges reactive oxygen species (ROS) before they react with $\mathrm{BH}_{4}$; or perhaps both. It is known that Asc is not capable of reducing $\mathrm{BH}_{2}$ [17]. It has been suggested that Asc could reduce $\mathrm{qBH}_{2}$, the short-lived intermediate in the oxidation of $\mathrm{BH}_{4}$, though there was no direct evidence for this mechanism [18-20]. Later on, it was suggested that thiols may reduce $\mathrm{qBH}_{2}$, while Asc reduces one-electron oxidized $\mathrm{BH}_{4}\left(\mathrm{BH}_{3}\right)$ [21]. Direct evidence for the reduction of $\mathrm{BH}_{3}$ by Asc has been obtained by pulse radiolysis [8] and EPR [7] and a rate constant of $1.7 \times 10^{5} \mathrm{M}^{-1} \mathrm{~s}^{-1}$ was determined [8].
Whereas an antioxidant activity may easily be demonstrated in vitro, it is much more difficult to prove that the reaction is also relevant in vivo. $\mathrm{BH}_{4}$ bound to NOS does become oxidized to $\mathrm{BH}_{3}$. during the catalytic cycle of NOS [22]. However, reduction of $\mathrm{BH}_{3}$ to $\mathrm{BH}_{4}$ is performed by NOS and does not involve Asc [22]. Whether freely circulating $\mathrm{BH}_{4}$ once oxidized is actually reduced by Asc in vivo remains to be established.

The second possibility that Asc protects $\mathrm{BH}_{4}$ from oxidation by scavenging ROS has also been explored. The ROS of particular relevance are superoxide, as it is formed by NOS when uncoupled, and peroxynitrite as it is formed by reaction between NO, the product of NOS, and superoxide. Superoxide reacts rather slowly with both ascorbate and $\mathrm{BH}_{4}$ with a rate contant of $3-4 \times 10^{5} \mathrm{M}^{-1} \mathrm{~s}^{-1}$ $[17,23]$. Superoxide, on the other hand, reacts rapidly with NO with a rate constant of the order of $10^{9}-10^{10} \mathrm{M}^{-1} \mathrm{~s}^{-1}$ [24-26] to produce peroxynitrite. Peroxynitrite has been shown to react 6-10 times faster with $\mathrm{BH}_{4}$ than with Asc [7]. Thus, in order for Asc to protect $\mathrm{BH}_{4}$ from oxidation by peroyxnitrite in vivo, Asc must be present at a much higher concentration than $\mathrm{BH}_{4}$. The micromolar concentration of Asc in plasma should be able to protect the nanomolar concentration of $\mathrm{BH}_{4}$ from oxidation by these two ROS. Inside endothelial cells the concentration of $\mathrm{BH}_{4}$ has been determined to be a few $\mathrm{pmol} / \mathrm{mg}$ protein $[20,27,28]$. Again, the much higher intracellular concentration of Asc compared to $\mathrm{BH}_{4}$-about three orders of magnitude [29-31]-means that Asc could kinetically protect $\mathrm{BH}_{4}$, but other systems such as superoxide dismutase may play a more prominent role in vivo.

\section{Ex vivo studies}

Concerning the interaction between $\mathrm{Asc}$ and $\mathrm{BH}_{4}$, three types of ex vivo studies have been performed: (1) studies involving NOS isolated from tissue, (2) studies involving cell cultures and (3) studies involving isolated tissues or organs. The primary focus of these studies has been to elucidate the mechanisms by which Asc may increase the bioavailability of NO.

\section{Nos}

Asc was found to increase the activity of iNOS as measured by the formation of L-citrulline, whereas dehydroascorbic acid at concentrations higher than $1 \mathrm{mM}$ decreased the activity of iNOS [32]. It was suggested that this was due to an antioxidant effect of Asc, in line with the finding that Asc also decreased the apparent $S_{0.5}$ value (the concentration at which the enzyme has half its maximal activity) of $\mathrm{BH}_{4}$ [32], i.e., less $\mathrm{BH}_{4}$ is needed if it's not becoming oxidized. Similarly, another study found that Asc increased the activity of eNOS in a concentration-dependent manner, as measured by

Table 1

Effect of Asc on the stability of $\mathrm{BH}_{4}$ in vitro.

\begin{tabular}{|c|c|c|c|c|}
\hline $\mathrm{BH}_{4}$ concentration $(\mu \mathrm{M})$ & Asc concentration $(\mu \mathrm{M})$ & Observation & Conditions & Reference \\
\hline 32.13 & 0 & $88 \%$ Breakdown & $20 \mathrm{~h}, 4^{\circ} \mathrm{C}, 0.1 \mathrm{M} \mathrm{HCl}$ & {$[16]$} \\
\hline 32.13 & 5700 & $0 \%$ Breakdown & $20 \mathrm{~h}, 4^{\circ} \mathrm{C}, 0.1 \mathrm{M} \mathrm{HCl}, \mathrm{Ar}$ & \\
\hline 0.0415 & 5700 & 0\% Breakdown & $4 \mathrm{~h}, 4^{\circ} \mathrm{C}, 0.1 \mathrm{M} \mathrm{HCl}, \mathrm{Ar}$ & \\
\hline 0.1 & 0 & $100 \%$ Breakdown & $20 \mathrm{~min}, \mathrm{RT}, \mathrm{pH} 7.4$ & {$[20]$} \\
\hline 0.1 & 100 & Half-life around $70 \mathrm{~min}$ & $\mathrm{RT}, \mathrm{pH} 7.4$ & \\
\hline 25 & 0 & 53\% Breakdown & $1 \mathrm{~h}, 22^{\circ} \mathrm{C}, \mathrm{pH} 7.4$ & [18] \\
\hline 25 & 500 & $46 \%$ Breakdown & $1 \mathrm{~h}, 22^{\circ} \mathrm{C}, \mathrm{pH} 7.4$ & \\
\hline 25 & 1500 & $35 \%$ Breakdown & $1 \mathrm{~h}, 22^{\circ} \mathrm{C}, \mathrm{pH} 7.4$ & \\
\hline 25 & 3000 & 7\% Breakdown & $1 \mathrm{~h}, 22{ }^{\circ} \mathrm{C}, \mathrm{pH} 7.4$ & \\
\hline 20 & 0 & $100 \%$ Breakdown & $0 \mathrm{~h}, 37^{\circ} \mathrm{C}, \mathrm{pH} 7.4$ & [38] \\
\hline 20 & 500 & $60 \%$ Breakdown & $21 \mathrm{~h}, 37^{\circ} \mathrm{C}, \mathrm{pH} 7.4$ & \\
\hline 36 & 0 & Half-life $17.5 \mathrm{~min}$ & 0.5 mM EDTA, $26^{\circ} \mathrm{C}, \mathrm{pH} 7.4$ & [19] \\
\hline 36 & 100 & Half-life around $25 \mathrm{~min}$ & $0.5 \mathrm{mM}$ EDTA, $26^{\circ} \mathrm{C}, \mathrm{pH} 7.4$ & \\
\hline
\end{tabular}

RT: room temperature. 
the formation of L-citrulline [28]. $\mathrm{BH}_{4}$ was also found to increase the activity of eNOS, as measured by the formation of L-citrulline, in microsomes prepared from human placental tissue; here, Asc enhanced the effect of $\mathrm{BH}_{4}$ on eNOS by an additional 40\% [18].

Cells

The cell types that have been studied are primarily endothelial cells but other cell types have been studied as well. Several studies have found that Asc enhanced the activity of NOS in intact cells. Increased formation of $\mathrm{L}$-citrulline in the presence of Asc is often used as a biomarker of enhanced NOS activity [20,28,33-37]. Other ways of assessing the activity of NOS in the presence of Asc are formation of nitrite and nitrate, oxidation products of NO [28,34,38,39], direct detection of NO [37] or cGMP, the latter formed by action of NO on soluble guanylate cyclase [33].

Several studies have found that Asc dose-dependently increased $\mathrm{NO}$ bioavailability and $\mathrm{BH}_{4}$ levels in endothelial cells (Table 2). It was found that Asc did not induce NOS expression in endothelial cells $[28,33,35,39]$ or in macrophages [38]. Likewise, it was found that Asc did not induce increased biosynthesis of $\mathrm{BH}_{4}[20,38]$ nor did Asc change the affinity of NOS towards $\mathrm{BH}_{4}$ [20]. The increase in $\mathrm{BH}_{4}$ was hence ascribed 'a stabilizing effect' of Asc on $\mathrm{BH}_{4}[20]$. Also, Asc did not enhance the cellular uptake of L-arginine [33], the substrate of NOS, nor did it change the $K_{\mathrm{m}}$ of L-arginine [28].

An increase in intracellular $\mathrm{BH}_{4}$ levels increased NO bioavailability $[20,28,35]$. The observed increase in $\mathrm{BH}_{4}$ levels induced by Asc may hence explain the increased NO bioavailability caused by Asc (Table 2). In addition to this effect of Asc, another mechanism has been suggested that enhances NO production without increasing $\mathrm{BH}_{4}$ levels. It was found that Asc increased phosphorylation of eNOS-Ser ${ }^{1177}$ and decreased phosphorylation of eNOS$\mathrm{Thr}^{495}$ and this correlated with an increased eNOS activity [36]. Intracellular $\mathrm{BH}_{4}$ levels did not increase until after four hours, but the increase in eNOS activity was seen already after 2-4 h incubation with Asc, and it was concluded that Asc may rapidly increase eNOS activity by phosphorylation/dephosphorylation and long-term by increasing $\mathrm{BH}_{4}$ levels [36].

Another potential mechanism involving eNOS activity has been proposed. Just like phosphorylation controls eNOS activity, so does S-nitrosylation. In a study, it was shown that S-nitrosylation inhibits eNOS activity in endothelial cells, and that eNOS S-nitrosylation correlated inversely with eNOS-Ser ${ }^{1177}$ phosphorylation [40]. Incubation of purified eNOS with Asc enhanced eNOS activity by $20 \%$ which correlated with a lower degree of eNOS S-nitrosylation [40] - the effect could not have been due to changes in phosphorylation status, as this requires the presence of phosphorylating enzymes [36]. Unfortunately, the effect of Asc on $\mathrm{BH}_{4}$ levels was not examined in this study.
Besides endothelial cells, the effect of Asc on NOS activity has been studied in cells of the immune system. In contrast to endothelial cells, which contain eNOS, cells of the immune system contain iNOS and nNOS [37]. Neutrophils from guinea pigs on an ascorbic acid-deficient diet for two weeks were found to contain less Asc and $\mathrm{BH}_{4}$ and have lower eNOS activity compared to neutrophils from control animals [37]. The expression of iNOS and nNOS was lower in neutrophils from Asc-deficient guinea pigs [37], whereas in endothelial cells, Asc did not influence eNOS expression (see above). Another study did not observe any changes in iNOS expression in mouse macrophage RAW 264.7 cells incubated with Asc, in contrast to a previous study that found a 2 -fold increase in iNOS levels in mouse macrophage J774.1 cells [41], but did find an increase in $\mathrm{BH}_{4}$ level and NOS activity [38]. Likewise, Asc in aqueous humor was found to increase nitrite formation in mice macrophages, an effect that was ascribed to a stabilizing effect on $\mathrm{BH}_{4}$ observed in the growth medium [42]. In polymorphonuclear leukocytes, both Asc and DHA were found to increase NOS activity [34].

\section{Tissues and organs}

A couple of studies have looked at the effect of $\mathrm{Asc}$ and $\mathrm{BH}_{4}$ on isolated tissues and organs. In excised aortas from rats, in which NOS had been inhibited in vivo by $\mathrm{N}^{\omega}$-nitro-L-arginine, sepiapterin, a precursor of $\mathrm{BH}_{4}$, was found to reduce vasodilation in contrast to what might be expected. The reduced vasodilation was believed to be due to autoxidation of $\mathrm{BH}_{4}$ caused by increased oxidative stress [43]. Incubation of the aortic rings with Asc $(1 \mu \mathrm{M})$ for $10 \mathrm{~min}$ restored vasodilation and this was suggested to be due to Asc stabilizing $\mathrm{BH}_{4}$ [43]. In another study, ascorbic acid ( $10 \mathrm{~g} / \mathrm{kg}$ chow) was given to wild-type and ApoE-deficient mice for 26-28 weeks. Whereas Asc increased acetylcholine-induced vasorelaxation in ApoE-deficient mice, it reduced vasorelaxation in wild-type mice [14]. In aortic homogenate, Asc in the diet increased L-citrulline formation in both wild-type and ApoE-deficient mice without affecting NOS expression, in line with the findings in endothelial cells (see above). Again, protection of $\mathrm{BH}_{4}$ by Asc was suggested to explain the findings [14]. The activity of eNOS and nNOS increased while iNOS activity decreased in ischemic rat muscle homogenate from rats fed $\mathrm{BH}_{4}$, $\mathrm{L}$-arginine and Asc (alone or in combination) with the largest change seen in the $\mathrm{BH}_{4}+\mathrm{L}$-arginine $+\mathrm{Asc}$ group [44]. This correlated with an increased eNOS expression and NO production found in vivo (see below). Okazaki et al. induced diabetes in rats and their hearts were isolated and perfused. $\mathrm{BH}_{4}$ and the $\mathrm{BH}_{4}$-to- $\mathrm{BH}_{2}$ ratio were decreased in the diabetic hearts whereas superoxide increased. Treatment with Asc increased the $\mathrm{BH}_{4}$-to- $\mathrm{BH}_{2}$ ratio, decreased superoxide production and increased nitrite and nitrate [45].

Table 2

Effect of Asc on eNOS activity and intracellular $\mathrm{BH}_{4}$ levels in endothelial cells.

\begin{tabular}{|c|c|c|c|c|c|}
\hline Cells & $\begin{array}{l}\text { Extracellular Asc } \\
(\mu \mathrm{M})\end{array}$ & $\begin{array}{l}\text { Intracellular Asc } \mathrm{pmol} / \mathrm{mg} \\
\text { protein }\end{array}$ & Effect on $\mathrm{BH}_{4}$ & Effect on NO bioavailability & Reference \\
\hline HUVEC & $0.1-100$ & 21,500 & n.d. & 3-Fold increase in L-citrulline and cGMP & [33] \\
\hline PAEC & 75 & 20,000 & Increased $126 \%$ & $\begin{array}{l}\text { 59-73\% Increase in cGMP, L-citrulline and nitrite/ } \\
\text { nitrate }\end{array}$ & [28] \\
\hline HUVEC & $1-1000$ & n.d. & 3-Fold increase & Dose-dependent increase of L-citrulline & {$[20]$} \\
\hline HUVEC & 100 & n.d. & 1.9-Fold increase & $\sim 50 \%$ Increase in L-citrulline & [35] \\
\hline HUVEC & 100 & n.d. & $\begin{array}{l}23 \% \text { (Not } \\
\text { significant) }\end{array}$ & n.d. & [54] \\
\hline BAEC & n.d. & $20-430$ & $20 \%$ Increase & 2-Fold increase of nitrite/nitrate & [39] \\
\hline $\begin{array}{l}\text { HUVEC } \\
\text { EA.hy926 }\end{array}$ & 100 & 4000 & $56 \%$ Increase & $\sim 50 \%$ Increase in L-citrulline & [36] \\
\hline
\end{tabular}

HUVEC: human umbilical vein endothelial cell; n.d.: not determined; PAEC: porcine aortic endothelial cell; BAEC: bovine aorta endothelial cells. 


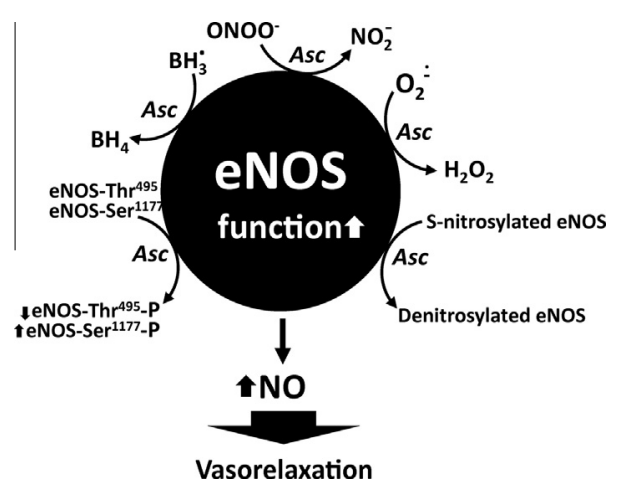

Fig. 3. Mechanisms by which Asc may improve vasorelaxation by increasing NO bioavailability through increased eNOS activity. See text for details.

\section{Asc enhancement of eNOS activity}

Based on the in vitro and ex vivo findings, the effect of Asc on eNOS activity may be summarized as in Fig. 3. Besides the reactions depicted in Fig. 3, Asc might also increase NO bioavailability in an eNOS-independent reaction by reducing nitrite, a degradation product of NO, to NO, a process utilized in the curing of meat. However, this reaction requires a low $\mathrm{pH}$, such as that found in the stomach, to proceed at an appreciable rate [46]. Hence, in the vasculature, enzymatic reduction of nitrite to NO is more likely than Asc-mediated reduction [47].

\section{In vivo studies}

Many studies have looked at the effect of either $\mathrm{BH}_{4}$ or Asc on endothelial function (for recent reviews see $[1,48]$. These studies have collectively shown that Asc and $\mathrm{BH}_{4}$ may individually increase the bioavailability of $\mathrm{NO}$ in vivo and improve clinical end points such as blood pressure and blood flow. However, this review will focus on studies in which $\mathrm{BH}_{4}$ and Asc have been administered and/or assayed together. Such combined experiments have been performed in both humans and animals. Whereas experiments in humans have mainly looked at clinical endpoints, animal experiments have mostly been concerned with measurements of NOS activity.

\section{Animals}

Guinea pigs, like humans, lack the ability to synthesize Asc and therefore completely rely on its presence in their diet [49]. Consequently, the guinea pig is a particularly well-suited animal model to study the possible interaction between vitamin $\mathrm{C}$ and $\mathrm{BH}_{4}$. Chatterjee and coworkers placed guinea pigs on a vitamin $C$ deficient diet for two weeks and found that, Asc in plasma and in neutrophils decreased by $80 \%$ and $78 \%$, respectively, compared to guinea pigs supplemented with $30 \mathrm{mg} /$ day [37]. As a result of the ascorbic acid-deficient diet, $\mathrm{BH}_{4}$ levels in neutrophils decreased by $60 \%$ [37]. The neutrophils were isolated and used for ex vivo studies (see above). Recently, we have demonstrated that plasma biopterin oxidation status is closely linked to the amount of Asc in plasma and hence in the diet in vivo [50]. In another study, guinea pigs were fed a diet containing either $100,250,500,750,1000$ or $1500 \mathrm{ppm}$ ascorbic acid. Those receiving 500-1500 ppm Asc had significantly higher plasma levels of $\mathrm{BH}_{4}$, than those receiving $100 \mathrm{ppm}$ and the group fed $100 \mathrm{ppm}$ Asc also had a higher $\mathrm{BH}_{2^{-}}$ to- $\mathrm{BH}_{4}$ ratio than all the other groups [50]. A positive linear correlation between plasma $\mathrm{BH}_{4}$ and plasma Asc was observed, whereas a negative correlation was observed between plasma $\mathrm{BH}_{4}$ and plas- ma DHA. $\mathrm{BH}_{2}$ plasma levels were not correlated with either Asc or DHA, whereas the $\mathrm{BH}_{4}$-to- $\mathrm{BH}_{2}$ ratio showed the same correlations as did $\mathrm{BH}_{4}[50]$.

Commonly used rodents such as mice and rats produce their own vitamin $C$ thereby potentially making supplementation studies difficult to interpret. Regardless, studies have also investigated the relationship between Asc and $\mathrm{BH}_{4}$ in these species. Similarly to the guinea pigs studies mentioned above, wild-type mice receiving feed containing $1 \%$ Asc more than tripled their $\mathrm{BH}_{4}$ in aorta with no effect on $\mathrm{BH}_{2}$ levels compared to controls [14]. In ApoE-deficient mice, on the other hand, $\mathrm{BH}_{4}$ levels in aorta were unaffected by supplementation with Asc, while $\mathrm{BH}_{2}$ levels decreased; however, neither $\mathrm{BH}_{4}$ nor $\mathrm{BH}_{2}$ levels in liver were affected by vitamin $\mathrm{C}$ supplementation [14]. In both cases, this resulted in an increased $\mathrm{BH}_{4}^{-}$ to- $\mathrm{BH}_{2}$ ratio which correlated with increased NOS activity as measured by the formation of L-citrulline [14].

Other studies have looked at the effect of increased bioavailability of Asc and $\mathrm{BH}_{4}$. Rats received $\mathrm{BH}_{4}$, L-arginine, $\mathrm{BH}_{4}+\mathrm{L}$-arginine or $\mathrm{BH}_{4}+\mathrm{L}$-arginine + ascorbic acid in their diet for one week after which hindlimb ischemia was induced. The rats fed either $\mathrm{BH}_{4}$ or L-arginine alone showed no improvement of blood flow recovery after induction of ischemia whereas those receiving either $\mathrm{BH}_{4}+\mathrm{L}$-arginine or $\mathrm{BH}_{4}+\mathrm{L}$-arginine + Asc showed a significant improvement [44]. This correlated with an increase in collateral artery diameter in rats receiving $\mathrm{BH}_{4}+\mathrm{L}$-arginine with an even greater increase when Asc was also included in the feed. Nitrite and nitrate, markers of $\mathrm{NO}$, were higher in rats fed $\mathrm{BH}_{4}+\mathrm{L}$-arginine and $\mathrm{BH}_{4}+\mathrm{L}$-arginine + Asc, and inclusion of Asc in the diet caused higher levels of nitrite and nitrate though it did not reach statistical significance (compared to the $\mathrm{BH}_{4}+\mathrm{L}$-arginine group), which correlated with an increase in eNOS expression [44]. Oxidative stress, measured as nitrotyrosine and ratio of glutathione to glutathione disulfide, was also lowest in the group receiving Asc [44]. In another study, ApoE-knockout mice overexpressing eNOS (leading to increased oxidative stress) were crossed with mice overexpressing the rate-limiting enzyme in the biosynthesis of $\mathrm{BH}_{4}$. This group was compared to ApoE-knockout mice overexpressing eNOS and to ApoE-knockout mice overexpressing eNOS who were given $500 \mathrm{mg}$ ascorbic acid/kg body weight/day [51]. The effect of increased $\mathrm{BH}_{4}$ biosynthesis was an increase in $\mathrm{BH}_{4}$ in aorta but without a concomitant increase in $\mathrm{BH}_{4}$-to- $\mathrm{BH}_{2}$ ratio; Asc had no effect on $\mathrm{BH}_{4}$ levels or $\mathrm{BH}_{4}$-to- $\mathrm{BH}_{2}$ ratio. $\mathrm{BH}_{4}$ increased the eNOS dimer-tomonomer ratio and decreased superoxide concentrations - Asc also decreased superoxide concentration but without altering the eNOS dimer-to-monomer ratio [51], indicating that Asc scavenges superoxide rather than changing the propensity for eNOS to produce superoxide. Overexpression of $\mathrm{BH}_{4}$ led to a decrease in atherosclerotic lesion formation whereas supplementing with Asc had no effect on atherosclerotic lesion formation in ApoE mice [51].

\section{Clinical studies}

For years, epidemiological studies have repeatedly shown that a poor vitamin C status is associated with increased risk of developing cardiovascular disease [52]. Fueled by the expanding in vitro literature supporting a role of Asc in maintaining $\mathrm{BH}_{4}$ reduced, we and others have speculated that increased NO availability mediated by reducing equivalents from Asc may be the missing link explaining the clinical observations [52]. However, so far only a very limited number of clinical studies have investigated the relationship between Asc and $\mathrm{BH}_{4}$.

In one study, people suffering from hypertension (systolic blood pressure $>135 \mathrm{mmHg}$ ) were given an oral combination of $\mathrm{BH}_{4}$ and Asc (200 mg of each twice daily or $100 \mathrm{mg}$ of each twice daily for four weeks). A significant decrease in systolic and mean blood pressure and an increase in flow-mediated vasodilation were ob- 
served [53]. The effect on blood pressure was ascribed to $\mathrm{BH}_{4}$ as a two week run-in period with Asc alone did not alter blood pressure. However, a combination effect of $\mathrm{BH}_{4}$ and Asc could not be ruled out [53].

Mittermayer and co-workers studied the effect of $\mathrm{BH}_{4}$ and Asc on forearm blood flow (FBF) responses to acetylcholine. Infusion of lipopolysaccharide caused a decrease in FBF response to acetylcholine of $23 \%$, but subsequent infusions of $\mathrm{BH}_{4}(500 \mu \mathrm{g} / \mathrm{min})$ or Asc $(24 \mu \mathrm{g} / \mathrm{min})$ restored FBF response to baseline values [54]. Asc did not increase systemic levels of $\mathrm{BH}_{4}$ but did cause a local $\mathrm{BH}_{4}$ increase in the forearm [54]. In a similar study, the effect of $\mathrm{BH}_{4}$ and Asc on FBF in chronic smokers was examined. $\mathrm{BH}_{4}$ infusion $(500 \mu \mathrm{g} / \mathrm{min}$ ) increased FBF response to acetylcholine and serotonin in smokers but not in non-smokers; Asc infusion (6 or $18 \mu \mathrm{g} /$ min) also improved FBF response to acetylcholine (the response to serotonin was not examined) [55]. Co-infusion of $\mathrm{BH}_{4}$ and Asc did not improve FBF compared to either agent alone and infusion of Asc prior to infusion of $\mathrm{BH}_{4}$ abolished the effect of $\mathrm{BH}_{4}$ [55].

As reviewed in detail elsewhere [48], vitamin C pharmacokinetics are highly dose dependent and ingestion of about $400 \mathrm{mg} /$ day result in a situation of near-saturation of plasma and tissues [10]. Thus, if adequately supplied through the diet, excess amounts achieved, e.g., by supplementation, are rapidly and effectively excreted. As discussed below, this issue is often overlooked in the clinical literature on vitamin C supplementation [56], and notably, none of the studies mentioned above enrolled subjects that were vitamin C deficient at study start. Consequently, they give no information on whether poor vitamin C status-a situation affecting substantial proportions of the World's population including the industrialized parts [56]-negatively affects the bioavailability of $\mathrm{BH}_{4}$ or if poor $\mathrm{BH}_{4}$ status can be ameliorated by vitamin $\mathrm{C}$ supplementation.

Looking more generally at cardiovascular health, almost all of the large phase III randomized controlled trials using vitamin C as intervention have not been able to demonstrate effect of vitamin C supplementation on cardiovascular morbidity or mortality [5761]. This constitutes a considerable discrepancy to the experimental and epidemiological literature. However, while experimental and epidemiological literature is generally weakened by their insufficient predictive validity, lack of ability to demonstrate causality in humans, and risk of unidentified confounders and co-deficiencies, the majority of the large clinical intervention studies suffers from several serious design issues including e.g., absence of vitamin C deficiency as inclusion criterion, no record of vitamin $C$ status before or after intervention, and unrecorded concurrent supplementation with vitamin $\mathrm{C}$ - also among placebo allocated individuals [52]. Thus, based on the information provided, the major vitamin $C$ intervention studies with cardiovascular endpoints have the serious weakness of studying populations with adequate to high vitamin $C$ levels at baseline. This renders them only able to confirm that supplementation to already well-nourished individuals is very likely to be without effect. Unfortunately, no trials have so far systematically studied the effect of vitamin C deficiency on cardiovascular risk or the effect of supplementation in this particularly relevant subpopulation. Consequently, it is not presently possible to evaluate to what extend the potential effects of vitamin $\mathrm{C}$ on $\mathrm{BH}_{4}$ status found experimentally are clinically relevant.

\section{Conclusion}

Asc has been shown to improve vasorelaxation in humans and animals. A number of studies have indicated that rather than a single mechanism, several different mechanisms appear to be involved in Asc-mediated vasorelaxation. Mainly, Asc may improve endothelial function by increasing $\mathrm{NO}$ bioavailability through $\mathrm{BH}_{4}$ and eNOS. Asc may increase $\mathrm{BH}_{4}$ bioavailability by protecting $\mathrm{BH}_{4}$ from being oxidized by scavenging ROS and/or by reducing oxidized $\mathrm{BH}_{4}$. Asc may also increase eNOS activity by changing its phosphorylation and S-nitrosylation status. However, although shown to occur ex vivo, it remains to be established to which extent these mechanisms are important in vivo.

\section{Conflicts of interest}

The authors declare no conflict of interest that could influence the present work.

\section{Acknowledgment}

This work was supported by the LIFEPHARM Centre for in vivo pharmacology.

\section{References}

[1] E.R. Werner, N. Blau, B. Thöny, Tetrahydrobiopterin: biochemistry and pathophysiology, Biochem. J. 438 (2011) 397-414.

[2] J. Vasquez-Vivar, Tetrahydrobiopterin, superoxide, and vascular dysfunction, Free Radic. Biol. Med. 47 (2009) 1108-1119.

[3] A. Mortensen, J. Lykkesfeldt, Kinetics of acid-induced degradation of tetra- and dihydrobiopterin in relation to their relevance as biomarkers of endothelial function, Biomarkers 18 (2013) 55-62.

[4] M.J. Crabtree, C.L. Smith, G. Lam, M.S. Goligorsky, S.S. Gross, Ratio of 5,6,7,8tetrahydrobiopterin to 7,8-dihydrobiopterin in endothelial cells determines glucose-elicited changes in NO vs. superoxide production by eNOS, Am. J. Physiol. Heart Circ. Physiol. 294 (2008) H1530-H1540.

[5] A. Presta, U. Siddhanta, C. Wu, N. Sennequier, L. Huang, H.M. Abu-Soud, S. Erzurum, D.J. Stuehr, Comparative functioning of dihydro- and tetrahydropterins in supporting electron transfer, catalysis, and subunit dimerization in inducible nitric oxide synthase, Biochemistry 37 (1998) 298310.

[6] J. Vásquez-Vivar, P. Martásek, J. Whitsett, J. Joseph, B. Kalyanaraman, The ratio between tetrahydrobiopterin and oxidized tetrahydrobiopterin analogues controls superoxide release from endothelial nitric oxide synthase: an EPR spin trapping study, Biochem. J. 362 (2002) 733-739.

[7] N. Kuzkaya, N. Weissmann, D.G. Harrison, S. Dikalov, Interactions of peroxynitrite, tetrahydrobiopterin, ascorbic acid, and thiols, J. Biol. Chem. 278 (2003) 22546-22554

[8] K.B. Patel, M.R.L. Stratford, P. Wardman, S.A. Everett, Oxidation of tetrahydrobiopterin by biological radicals and scavenging of the trihydrobiopterin radical by ascorbate, Free Radic. Biol. Med. 32 (2002) $203-$ 211.

[9] J. Lykkesfeldt, M. Viscovich, H.E. Poulsen, Ascorbic acid recycling in human erythrocytes is induced by smoking in vivo, Free Radic. Biol. Med. 35 (2003) 1439-1447.

[10] B. Frei, I. Birlouez-Aragon, J. Lykkesfeldt, What is the optimum intake of vitamin C in humans?, Crit Rev. Food Sci. Nutr. 52 (2012) 815-829.

[11] M. Takeda, T. Yamashita, M. Shinohara, N. Sasaki, T. Takaya, K. Nakajima, N. Inoue, T. Masano, H. Tawa, S. Satomi-Kobayashi, R. Toh, D. Sugiyama, K. Nishimura, M. Yokoyama, K.i. Hirata, S. Kawashima, Plasma tetrahydrobiopterin/dihydrobiopterin ratio: a possible marker of endothelial dysfunction, Circ. J. 73 (2009) 955-962.

[12] K. Noguchi, N. Hamadate, T. Matsuzaki, M. Sakanashi, J. Nakasone, T. Uchida, K. Arakaki, H. Kubota, S. Ishiuchi, H. Masuzaki, K. Sugahara, Y. Ohya, M. Sakanashi, M. Tsutsui, Increasing dihydrobiopterin causes dysfunction of endothelial nitric oxide synthase in rats in vivo, Am. J. Physiol. Heart Circ. Physiol. 301 (2011) H721-H729.

[13] M.V. Tsapenko, L.V. d'Uscio, J.P. Grande, A.J. Croatt, M.C. Hernandez, A.W. Ackerman, Z.S. Katusic, K.A. Nath, Increased production of superoxide anion contributes to dysfunction of the arteriovenous fistula, Am. J. Physiol. Renal Physiol. 303 (2012) F1601-F1607.

[14] L.V. d'Uscio, S. Milstien, D. Richardson, L. Smith, Z.S. Katusic, Long-term vitamin $C$ treatment increases vascular tetrahydrobiopterin levels and nitric oxide synthase activity, Circ. Res. 92 (2003) 88-95.

[15] S. Kar, M. Kavdia, Modeling of biopterin-dependent pathways of eNOS for nitric oxide and superoxide production, Free Radic. Biol. Med. 51 (2011) 1411 1427.

[16] D.W. Howells, K. Hyland, Direct analysis of tetrahydrobiopterin in cerebrospinal fluid by high-performance liquid chromatography with redox electrochemistry: prevention of autoxidation during storage and analysis, Clin. Chim. Acta 167 (1987) 23-30.

[17] J. Vásquez-Vivar, J. Whitsett, P. Martásek, N. Hogg, B. Kalyanaraman, Reaction of tetrahydrobiopterin with superoxide: EPR-kinetic analysis and characterization of the pteridine radical, Free Radic. Biol. Med. 31 (2001) 975-985. 
[18] M. Tóth, Z. Kukor, S. Valent, Chemical stabilization of tetrahydrobiopterin by Lascorbic acid: contribution to placental endothelial nitric oxide synthase activity, Mol. Hum. Reprod. 8 (2002) 271-280.

[19] S. Valent, M. Toth, Spectrophotometric analysis of the protective effect of ascorbate against spontaneous oxidation of tetrahydrobiopterin in aqueous solution: kinetic characteristics and potentiation by catalase of ascorbate action, Int. J. Biochem. Cell Biol. 36 (2004) 1266-1280.

[20] R. Heller, A. Unbehaun, B. Schellenberg, B. Mayer, G. Werner-Felmayer, E.R. Werner, L-Ascorbic acid potentiates endothelial nitric oxide synthesis via a chemical stabilization of tetrahydrobiopterin, J. Biol. Chem. 276 (2001) 40-47.

[21] S. Valent, M. Tóth, Activation energy determinations suggest that thiols reverse autooxidation of tetrahydrobiopterin by a different mechanism than ascorbate, Int. J. Biochem. Cell Biol. 38 (2006) 1786-1793.

[22] C.C. Wei, Z.Q. Wang, J. Tejero, Y.P. Yang, C. Hemann, R. Hille, D.J. Stuehr, Catalytic reduction of a tetrahydrobiopterin radical within nitric-oxide synthase, J. Biol. Chem. 283 (2008) 11734-11742.

[23] N. Gotoh, E. Niki, Rates of interactions of superoxide with vitamin E, vitamin C and related compounds as measured by chemiluminescence, Biochim. Biophys. Acta 1115 (1992) 201-207.

[24] R.E. Huie, S. Padmaja, The reaction of NO with superoxide, Free Radic. Res. Commun. 18 (1993) 195-199.

[25] S. Goldstein, G. Czapski, The reaction of NO with $\mathrm{O}_{2}$ and $\mathrm{HO}_{2}$ - a pulseradiolysis study, Free Radic. Biol. Med. 19 (1995) 505-510.

[26] K. Kobayashi, M. Miki, S. Tagawa, Pulse-radiolysis study of the reaction of nitric oxide with superoxide, J. Chem. Soc., Dalton Trans. (1995) 2885-2889.

[27] J. Whitsett, M.J. Picklo Sr., J. Vasquez-Vivar, 4-Hydroxy-2-nonenal increases superoxide anion radical in endothelial cells via stimulated gtp cyclohydrolase proteasomal degradation, Arterioscler. Thromb. Vasc. Biol. 27 (2007) 23402347.

[28] A. Huang, J.A. Vita, R.C. Venema, J.F. Keaney, Ascorbic acid enhances endothelial nitric-oxide synthase activity by increasing intracellular tetrahydrobiopterin, J. Biol. Chem. 275 (2000) 17399-17406.

[29] E. Alexandra, K. Ström, I.A. Cotgreave, The uptake of ascorbic acid into human umbilical vein endothelial cells and its effect on oxidant insult, Biochem. Pharmacol. 50 (1995) 1339-1346.

[30] A. Martin, B. Frei, Both intracellular and extracellular vitamin C inhibit atherogenic modification of ldl by human vascular endothelial cells, Arterioscler. Thromb. Vasc. Biol. 17 (1997) 1583-1590.

[31] K.A. Best, M.E. Holmes, S.E. Samson, J. Mwanjewe, J.X. Wilson, S.J. Dixon, A.K. Grover, Ascorbate uptake in pig coronary artery endothelial cells, Mol. Cell. Biochem. 271 (2005) 43-49.

[32] H. Hofmann, H.H.H.W. Schmidt, Thiol dependence of nitric oxide synthase, Biochemistry 34 (1995) 13443-13452.

[33] R. Heller, F. Münscher-Paulig, R. Gräbner, U. Till, L-Ascorbic acid potentiates nitric oxide synthesis in endothelial cells, J. Biol. Chem. 274 (1999) 8254-8260.

[34] P. Sharma, S.A.V. Raghavan, M. Dikshit, Role of ascorbate in the regulation of nitric oxide generation by polymorphonuclear leukocytes, Biochem. Biophys. Res. Commun. 309 (2003) 12-17.

[35] T.A. Baker, S. Milstien, Z.S. Katusic, Effect of vitamin C on the availability of tetrahydrobiopterin in human endothelial cells, J. Cardiovasc. Pharmacol. 37 (2001) 333-338.

[36] A. Ladurner, C.A. Schmitt, D. Schachner, A.G. Atanasov, E.R. Werner, V.M. Dirsch, E.H. Heiss, Ascorbate stimulates endothelial nitric oxide synthase enzyme activity by rapid modulation of its phosphorylation status, Free Radic. Biol. Med. 52 (2012) 2082-2090.

[37] M. Chatterjee, R. Saluja, V. Kumar, A. Jyoti, G. Kumar, M. Jain, M. Kumar Barthwal, Dikshit, Ascorbate sustains neutrophil NOS expression, catalysis, and oxidative burst, Free Radic. Biol. Med. 45 (2008) 1084-1093.

[38] K. Nakai, M. Urushihara, Y. Kubota, H. Kosaka, Ascorbate enhances iNOS activity by increasing tetrahydrobiopterin in RAW 264.7 cells, Free Radic. Biol. Med. 35 (2003) 929-937.

[39] H.J. Kim, S.I. Lee, D.H. Lee, D. Smith, H. Jo, H.E. Schellhorn, Y.C. Boo, Ascorbic acid synthesis due to L-gulono-1,4-lactone oxidase expression enhances NO production in endothelial cells, Biochem. Biophys. Res. Commun. 345 (2006) 1657-1662.

[40] P.A. Erwin, A.J. Lin, D.E. Golan, T. Michel, Receptor-regulated dynamic Snitrosylation of endothelial nitric-oxide synthase in vascular endothelial cells, J. Biol. Chem. 280 (2005) 19888-19894.

[41] A. Mizutani, H. Maki, Y. Torii, K. Hitomi, N. Tsukagoshi, Ascorbate-dependent enhancement of nitric oxide formation in activated macrophages, Nitric Oxide 2 (1998) 235-241.
[42] K.C. McKenna, K.M. Beatty, R.C. Scherder, F. Li, H. Liu, A.F. Chen, A. Ghosh, D.J. Stuehr, Ascorbate in aqueous humor augments nitric oxide production by macrophages, J. Immunol. 190 (2013) 556-564.

[43] B.M. Mitchell, A.M. Dorrance, A. Ergul, R.C. Webb, Sepiapterin decreases vasorelaxation in nitric oxide synthase inhibition-induced hypertension, J. Cardiovasc. Pharmacol. 43 (2004) 93-98.

[44] J. Yan, G. Tie, L.M. Messina, Tetrahydrobiopterin, L-arginine and vitamin C act synergistically to decrease oxidative stress, increase nitric oxide and improve blood flow after induction of hind limb ischemia in the rat (vol 18, pg 1221, 2012), Mol. Med. 18 (2012) 1221-1230.

[45] T. Okazaki, H. Otani, T. Shimazu, K. Yoshioka, M. Fujita, T. Iwasaka, Ascorbic acid and $\mathrm{N}$-acetyl cysteine prevent uncoupling of nitric oxide synthase and increase tolerance to ischemia/reperfusion injury in diabetic rat heart, Free Radic. Res. 45 (2011) 1173-1183.

[46] K. Izumi, R.G. Cassens, M.L. Greaser, Reaction of nitrite with ascorbic acid and its significant role in nitrite-cured food, Meat Sci. 26 (1989) 141-153.

[47] J.O. Lundberg, E. Weitzberg, Nitrite reduction to nitric oxide in the vasculature, Am. J. Physiol. Heart Circ. Physiol. 295 (2008) H477-H478.

[48] H. Frikke-Schmidt, J. Lykkesfeldt, Role of marginal vitamin C deficiency in atherogenesis. In vivo models and clinical studies, Basic Clin. Pharmacol. Toxicol. 104 (2009) 419-433.

[49] P. Tveden-Nyborg, S. Hasselholt, N. Miyashita, T. Moos, H.E. Poulsen, J. Lykkesfeldt, Chronic vitamin C deficiency does not accelerate oxidative stress in ageing brains of guinea pigs, Basic Clin. Pharmacol. Toxicol. 110 (2012) 524-529.

[50] A. Mortensen, S. Hasselholt, P. Tveden-Nyborg, J. Lykkesfeldt, Ascorbate status predicts tetrahydrobiopterin plasma concentration and oxidation ratio in vivo, Nutr. Res. 33 (2013) 859-867.

[51] T. Takaya, K.i. Hirata, T. Yamashita, M. Shinohara, N. Sasaki, N. Inoue, T. Yada, M. Goto, A. Fukatsu, T. Hayashi, N.J. Alp, K.M. Channon, M. Yokoyama, S. Kawashima, A specific role for eNOS-derived reactive oxygen species in atherosclerosis progression, Arterioscler. Thromb. Vasc. Biol. 27 (2007) 16321637.

[52] P. Tveden-Nyborg, J. Lykkesfeldt, Does vitamin C deficiency Increase lifestyleassociated vascular disease progression? Evidence based on experimental and clinical studies, Antioxid. Redox Sign.

[53] M. Porkert, S. Sher, U. Reddy, F. Cheema, C. Niessner, P. Kolm, D.P. Jones, C. Hooper, W.R. Taylor, D. Harrison, A.A. Quyyumi, Tetrahydrobiopterin: a novel antihypertensive therapy, J. Hum. Hypertens. 22 (2008) 401-407.

[54] F. Mittermayer, J. Pleiner, G. Schaller, S. Zorn, K. Namiranian, S. Kapiotis, G. Bartel, M. Wolfrum, M. Brügel, J. Thiery, R.J. MacAllister, M. Wolzt, Tetrahydrobiopterin corrects Escherichia coli endotoxin-induced endothelial dysfunction, Am. J. Physiol. Heart Circ. Physiol. 289 (2005) H1752-H1757.

[55] T. Heitzer, C. Brockhoff, B. Mayer, A. Warnholtz, H. Mollnau, S. Henne, T. Meinertz, T. Münzel, Tetrahydrobiopterin improves endothelium-dependent vasodilation in chronic smokers: evidence for a dysfunctional nitric oxide synthase, Circ. Res. 86 (2000) e36-e41.

[56] J. Lykkesfeldt, H.E. Poulsen, Is vitamin C supplementation beneficial? lessons learned from randomised controlled trials, Br. J. Nutr. 103 (2010) 1251-1259.

[57] W.J. Blot, J.Y. Li, P.R. Taylor, W. Guo, S. Dawsey, G.Q. Wang, C.S. Yang, S.F. Zheng, M. Gail, G.Y. Li, Y. Yu, B.q. Liu, J. Tangrea, Y.h. Sun, F. Liu, J.F. Fraumeni, Y.H. Zhang, B. Li, Nutrition intervention trials in Linxian, China: supplementation with specific vitamin/mineral combinations, cancer incidence, and disease-specific mortality in the general population, J. Natl. Cancer I (85) (1993) 1483-1491.

[58] N.R. Cook, C.M. Albert, J.M. Gaziano, E. Zaharris, J. MacFadyen, E. Danielson, J.E. Buring, J.E. Manson, A randomized factorial trial of vitamins $C$ and $E$ and beta carotene in the secondary prevention of cardiovascular events in women: results from the women's antioxidant cardiovascular study, Arch. Intern. Med. 167 (2007) 1610-1618.

[59] Heart Protection Study Collaborative Group, MRC/BHF heart protection study of antioxidant vitamin supplementation in 20536 high-risk individuals: a randomised placebo-controlled trial, Lancet 360 (2002) 23-33.

[60] S. Hercberg, P. Galan, P. Preziosi, S. Bertrais, L. Mennen, D. Malvy, A.-M. Roussel, A. Favier, S. Briançon, The SU.VI.MAX study: A randomized, placebocontrolled trial of the health effects of antioxidant vitamins and minerals, Arch. Intern. Med. 164 (2004) 2335-2342.

[61] H.D. Sesso, J.E. Buring, W.G. Christen, T. Kurth, C. Belanger, J. MacFadyen, V. Bubes, J.E. Manson, R.J. Glynn, J.M. Gaziano, Vitamins E and C in the prevention of cardiovascular disease in men: the physicians' health study II randomized controlled trial, JAMA 300 (2008) 2123-2133. 